\title{
$\angle$ Research Square \\ Are Tryptophan and Serotonin Alteration Act as a Trigger Biomarker for Type 2 Diabetes Complications?
}

Kamyar Khoshnevisan ( $\nabla$ kamyar.khoshnevisan@gmail.com )
Tehran University of Medical Sciences https://orcid.org/0000-0003-1250-4292

Maryam Chehrehgosha

University of Social Welfare and Rehabilitation Science

Sayed Mahmoud Sajjadi-Jazi

Tehran University of Medical Sciences Endocrinology and Metabolism Research Institute

\section{Research Article}

Keywords: Tryptophan, Serotonin, Diabetes mellitus, Insulin, complications

Posted Date: June 24th, 2021

DOI: https://doi.org/10.21203/rs.3.rs-609749/v1

License: (9) This work is licensed under a Creative Commons Attribution 4.0 International License. Read Full License 


\section{Abstract}

Tryptophan (Trp) is a vital amino acid causing clinical implications in the human body and biological specimens. Serotonin (5-HT) is well-recognized for its biological activities in the brain, and as a familiar neurotransmitter, it regulates various neuropsychological processes. Alterations in the serotonergic system were proved to play a role in the pathogenesis of different neurological and psychiatric diseases. In recent years, Trp and 5-HT levels have been considered as triggers of diabetes mellitus (DM). The altered Trp metabolism may also play roles in the pathogenesis of DM and developing a risk of complications. The whole blood (WB) 5-HT level was mainly lower among diabetic patients compared to others. That is mostly derived from a lower platelet concentration of 5-HT in these patients. Indeed, $5-\mathrm{HT}$ level can be considered as a potent biomarker for early detection of DM complications. Besides, it was proved that outside the digestive and central nervous systems, 5 -HT was discovered in beta cells, and scientists have been attempting to realize its mechanism of action ever since. Towards to end, the determination methods, biomarker's role, and approaches of 5-HT and Trp levels were thoroughly investigated in both healthy and diabetic patients with or without complications. Moreover, the association between insulin and 5-HT has been specifically discussed. Our study concluded that Trp and 5-HT levels could be exclusively applied for early diagnosis of DM complications as well as many other complications.

\section{Introduction}

\subsection{Tryptophan and serotonin}

Tryptophan (Trp) is a vital amino acid causing clinical implications in the human body and biological specimens. Moreover, Trp is recommended to be used as a medication for disorders such as insomnia, anxiety, addiction, and obesity. Recently, Trp level has been considered as a biomarker for diabetes discovery.

Serotonin (5-HT, feel-good hormone) is well-recognized for its biological activities in the brain, and as a familiar neurotransmitter, it regulates a variety of neuropsychological processes [1]. Alterations in serotonergic system were proved to provide a role in pathogenesis of different neurological and psychiatric diseases [1]. Recently, serotonin dysregulation was linked to the pathogenesis of diabetes mellitus (DM). In addition, this was found in beta cells and some previous studies showed that serotonin signaling is significant in insulin release, and the absence of 5-HT can consequently lead to diabetes [2]. Besides, several studies suggested that the whole blood (WB) serotonin level is lower among diabetic patients, especially in those with DM complications such as retinopathy [3], nephropathy [4], and peripheral vascular diseases [5]. Besides, the WB 5-HT level was mainly lower among diabetic patients. Accordingly, this is mostly derived from a lower platelet concentration of $5-\mathrm{HT}$ in these patients [3]. Indeed, 5-HT level may be considered as a useful biomarker for early detection of DM complications [4].

\subsection{Determination methods}

Up to now, several methods such as high performance liquid chromatography (HPLC), tandem mass spectrometry (MS-MS), fluorescence, spectrophotometry, fluorometry, gas chromatography-mass spectrometry (GC-MS), and electrochemical sensing, have been applied to measure 5-HT and Trp, as well as some other analytes with similar chemical structures $[6,7]$. Figure 1 represents an outline of the most common methods 
used for the detection of both Trp and 5-HT. Accordingly, among these methods, electrochemical sensing approaches have received much attention due to their easiness, high sensitivity, selectivity, and inexpensive determination of medical biomolecules [8]. As well, it is believed that the electrochemical method can be applied as a reliable method for the detection of medical analytes such as amino acids and neurotransmitters in the clinical lab [9]. In addition, nanomaterials-based electrochemical sensing of both Trp and 5-HT have been exclusively investigated in order to determine their levels in both animal models and biological fluid of the human body.

\subsection{Biomarker role of $5-\mathrm{HT}$ and Trp}

It was shown that $5-\mathrm{HT}$, as a biomarker, plays noteworthy roles in some main diseases such as autism spectrum disorder (ASD), attention-deficit hyperkinetic disorders (AD-HKD), coronary microvascular dysfunction (CMD), atherosclerotic cardiovascular disease (ASCVD), chronic heart failure (CHF), and vascular complications in DM [10-12]. In this regard, the WB 5-HT level was also found to be mainly lower among diabetic patients. That is mostly derived from a lower platelet concentration of 5-HT in these patients. Indeed, 5-HT level may be considered as a useful biomarker for early detection of diabetes mellitus complications. Besides, it was proved that outside the digestive and central nervous systems, 5-HT can be discovered in beta cells, and found that it acts as a potent tool to regulate insulin release.

The role of Trp metabolism in inflammation disorders was also observed; however, there is limited evidence on the determination of Trp yet [13]. Observational studies have previously proposed that Trp metabolism could be exploited as a biomarker for inflammation disorders [14]. In the case of DM, the altered L-Trp metabolism may play roles in the pathogenesis of DM and developing the risk of complications. Based on recent data regarding this, the Trp metabolic pathway could be considered as an appropriate marker for the progression of novel antidiabetic drugs. Besides, it was found that Trp metabolism could be applied as therapeutic targets to control age-related diseases related to inflammation and probably even to extend lifespan.

It is believed that the Trp and 5-HT levels can be potentially applied as biomarkers for early diagnosis of DM as well as many other disorders $[15,16]$. Herein, we attempted to provide a comprehensive summary on the relationship between Trp and 5-HT with DM as well as finding the existent mechanisms between insulin and 5HT.

\section{Determination Of 5-ht Level As A Dm Trigger}

5-HT level could be considered as a marker for early detection of diabetes mellitus complications. Several studies have previously suggested that the WB 5-HT level is lower among diabetic patients, especially in those with DM complications such as retinopathy, nephropathy, and peripheral vascular diseases $[3,5,17]$. Due to the significance of 5-HT level and its relationship with DM complications, it is exclusively represented as a potent diabetes tool in this section. A schematic was also provided to demonstrate the direct effect of the reduced 5$\mathrm{HT}$ level on the stimulation of liver, and adipose tissue; however, skeletal muscle can be provoked indirectly. As well, it seems that different mechanisms could lead to obesity, metabolic disorders, lipid accumulation, insulin sensitivity, and resistance in the human body (Fig. 2). 
In a previous study, 5-HT level was successfully measured as a novel diabetes biomarker using a simple nanocomposite comprising of the reduced graphene oxide (rGO), gold nanoparticles (AuNPs), and 18-crown-6 (18.Cr.6) by HPLC method in zebrafish, as a novel animal model. As a result, the most diminution in 5-HT level was observed in diabetic zebrafish compared to the normal group. Moreover, this study verified that the 5-HT level can be employed as a potent biomarker used for the early diagnosis of DM [16].

The directed and undirected metabolomics' procedures were used to examine plasma and urine samples of pregnant women with and without gestational diabetes mellitus (GDM). This study displayed that serotonin and the associated metabolites significantly varied among the controls and patients, approving the relationship of 5-HT metabolism in GDM [18].

Saito et al. in their study registered 165 Type 2 diabetes (T2D), including 106 normoalbuminuric and 59 microalbuminuric patients, in order to investigate multivariate analyses. Thus, it was indicated that the increased plasma 5-hydroxyindole-3-acetic acid (5-HIAA) levels are involved in the pathogenesis of impaired blood flow in lower extremities and renal insufficiency among diabetic patients with microalbuminuria [19].

In an exploratory study, the associations amongst cortisol parameters, platelet 5-HT content, and platelet activity markers were testified in patients with major depression (MD) and/or T2D. Finally, the results showed that augmented platelet activity in T2D could play a role in the relationship amongst diabetes, depression, and coronary artery disease (CAD) [20].

Hara et al. in their study evaluated plasma 5-HT levels in patients with the DM complicated with chronic kidney disease disposed to atherosclerosis. The results proved that platelets are stimulated to release 5-HT into plasma among patients with moderate diabetes and the damaged renal role. Moreover, platelets can be overactivated to release 5 -HT in patients with severe diabetes [17].

An observational study was conducted on 162 male patients with T2D, in order to examine if plasma 5-HIAA level, as a derivative final version of $5-\mathrm{HT}$, may be considered as an interpreter for decline of urinary albumin expulsion. So, for this purpose, the association between baseline plasma 5-HIAA level and alterations in urinary albumin was inspected for a 24-month duration. This observational study proved that plasma 5-HIAA concentration is associated with alterations in urinary albumin excretion, pointing out a causality in complicated diabetic nephropathy with T2D and a high plasma 5-HIAA concentration [21].

In another study, the Framingham 10-year risk scores (FRS) of 30-74 years old issues were considered, and some clinical characteristics such as age, sex, blood pressure, smoking, and diabetes status were then combined into the measurement. Plasma 5-HT levels were found to be significantly correlated with FRS. The association of the declined brachial-ankle pulse wave velocity (baPWV) in diabetic patients with the promotion of plasma 5-HT levels was successfully obtained, describing an important association between plasma 5-HT and atherosclerosis [22].

As alluded to the above-mentioned statements, it is believed that 5-HT/5-HIAA levels in plasma and WB are valuable biomarkers for predicting the risk of developing vascular complications and depression in patients with DM. In conclusion to this section, in the current study, we explored that 5-HT/5-HIAA levels could be exploited as a potential biomarker in patients at early stages of DM complications. The determination method, 
sample type, and the main finding obtained from 5-HT/5HIAA levels in the patients with DM are shown in Table 1.

\section{Determination Of Trp Level As A Dm Trigger}

Accumulating data showed that the changes in metabolism of Trp and its active metabolites play essential roles in both the pathogenesis and complications of diabetes [23]. The altered L-Trp metabolism may play a role in the pathogenesis of diabetes mellitus and developing the risk of complications. Some previous studies have suggested that Trp decreased and its metabolism up-regulates in diabetic patients [24,25]. Based on studies performed on the relationship between Trp and diabetes, the related studies on human and animal samples have been selected, the details of which are explained below:

In another study, L- Trp level was assessed in diabetic and normal serum samples in human using the reduced graphene oxide/gold nanoparticles/18-crown-6. Based on the square wave voltammetry (SWV) results, a low limit of detection (LOD) was calculated as about $0.48 \mu \mathrm{M}$ and $0.61 \mu \mathrm{M}$ for diabetic and normal samples, respectively. It seems that the nanocomposite could be known as a good choice for L-Trp determination in human serum [15]. In another study, C-mannosyl tryptophan (C-Man-Trp) was measured in different tissues obtained from normal or diabetic mice. The increased excretion of C-Man-Trp level was also observed in urine and kidney tissue; however, C-Man-Trp levels reduced in the liver of diabetic mice. Correspondingly, these results suggested that C-Man-Trp metabolism is greatly affected by diabetes [26].

Chou et al. in their study evaluated serum levels of various metabolites among diabetic patients at various stages of chronic kidney disease. It was shown that Lower Trp levels are associated with a rapid drop in the estimated glomerular filtration rate (eGFR). Moreover, this study exhibited that Trp level might be considered as a potential biomarker for diabetic nephropathy [27].

In the Rebnord et al.'s study, the associations of the kynurenine (KYN): Trp ratio (KTR) to the occurrence of diabetes type 2, was considered. Thereafter, the plasma and urine samples of studied individuals with coronary artery disease were obtained, and the levels of KYN and Trp were then measured. Although the results showed no significant relationship between KTR and type 2 diabetes in Plasma samples, was a strong positive association was found between KTR and type 2 diabetes in urine samples [28].

Chen et al. in their study evaluated the role of Trp, as a predicting risk factor for T2D outcomes, in healthy and diabetic Chinese men. Accordingly, their results showed that serum Trp level was significantly higher among diabetic patients, and Trp biomarker was associated with DM onset risk positively and independently. It was indicated that the higher Trp levels in these patients can make higher levels of both insulin resistance and secretion. These findings revealed the potential of Trp as a new biomarker of diabetes risk in the Chinese population [29].

\subsection{Determination of L-Trp as a biomarker of diabetes in old age}

It was found that aging changes the composition and function of adipose tissue, and consequently leads to insulin resistance and fat storage in the ectopic body part [30]. The cellular changes that converge during the 
aging process are dysfunction in mitochondria, antioxidant deficiency, inflammation, and the decreased immune response. Accordingly, these changes affect the KYN pathway (KP) (Fig. 3), which is known as a major pathway for Trp catabolism [31].

Some studies have previously reported that Trp metabolites play a key role as a potential biological mediator for T2D $[29,32,33]$. Trp metabolism is thought to be altered due to various physiological and psychological pressures such as self-care in diabetic patients [34]. These findings exhibited the possible role of Trp in geriatric diabetic patients.

In a study, Trp metabolites were assessed in healthy and diabetic adult men. The results confirmed that 5hydroxytryptophan (5-HTP) levels were higher in diabetic patients compared to healthy adult men [35].

Calvani et al. in their study determined the circulating amino acids in diabetic frail adults, in order to detect the concentrations of circulating 37 amino acids. They reported high Trp levels in serum samples of diabetic adults compared to their control participants [36]. In another study, the measurement of Trp, KYN, and neopterin levels as immune activation markers in volunteers aged $\geq 65$ and $<65$ years old, was performed. The geriatric groups had low Trp levels compared to the young groups. Conversely, Trp and KYN/Trp levels were found to be significantly higher than adults without DM [37].

In a research, Shimizu et al. evaluated the Trp metabolites in plasma samples obtained from both young and old participants with and without type 2 diabetes. Plasma Trp metabolites levels in young women and old men were found to be higher than young men and old women. Except the KYN and indole butyric acid, the plasma levels of Trp metabolites were higher in diabetic patients than adult men [34]. Furthermore, Matsuoka et al. presented various Trp metabolites in diabetic and healthy men. Accordingly, their results showed that the plasma level of Trp in diabetic adults was lower than that of healthy subjects, but it was not statistically significant. As well, 5-HTP concentration and the other related Trp metabolites were statistically higher in diabetic adults [25].

As shown in most of the results, in human serum and plasma samples, the amount of Trp was higher in diabetic peoples compared to healthy ones. It seems that T2D is characterized by low-grade systemic inflammation, which consequently affects adipose tissue, the liver, pancreas, and kidneys [38]. On the other hand, degradation of Trp also appears to be closely related to the immune system activation [39]. Besides, KYN pathway activity significantly increased in chronic stress [40]. Correspondingly, all these factors manifested themselves by growing the Trp degradation in a patient's serum. Altogether, our observations indicated that the Trp levels have been previously evaluated in different samples, participants, and disease stages in various studies. Unfortunately, there was a few studies on determining the role of Trp in diabetic patients; therefore, it is hard to speak about the exact changes of Trp levels and their metabolites in different study samples. More information on methodology and the obtained results are mentioned in Table 2.

\section{Association Between 5-ht And Insulin: Role In Dm}

It was verified that outside the digestive and central nervous systems, 5-HT can also be discovered in pancreatic beta cells, and scientists have been attempting to realize its mechanism of action ever since $[41,42]$. 
5-HT is synthesized and then stored in pancreatic beta cells and co-released with insulin by glucose stimulation of beta cells $[43,44]$.

Several studies indicated that $5-\mathrm{HT}$ is essential for glucose-dependent insulin secretion and the lack of 5-HT in pancreatic beta cells consequently causes hyperglycemia and diabetes mellitus [45-48]. In this regard, several mechanisms have been proposed to explain the $5-\mathrm{HT}$ role in the regulation of both insulin secretion and glucose hemostasis. Moon et al. in their study indicated that growth hormone $(\mathrm{GH})$ could mediate expression of tryptophan hydroxylase 1 , which is a key enzyme in the synthesis of $5-\mathrm{HT}$, and consequently the production of 5-HT can be stimulated in pancreatic beta cells during the perinatal period. Accordingly, in perinatal period, $5-\mathrm{HT}$ acts as a paracrine/autocrine regulator in inducing the proliferation of beta cells through the $5-\mathrm{HT} 2 \mathrm{~B}$ receptor.

The amount of cell proliferation achieved during the perinatal period, is one of the major determinants of adult beta-cell mass, in such way that those with lower beta-cell mass have a higher susceptibility to diabetes [49]. Additionally, Ohara-Imaizumi et al. in their study showed that 5-HT can lower glucose threshold for insulin release and also increase glucose-stimulated insulin secretion from beta cells via the 5-HT3 receptor in an autocrine/paracrine manner during pregnancy. Therefore, the authors suggested that 5-HT may play a role in the pathogenesis of gestational diabetes [50]. Other reports have also confirmed the regulatory effects of 5-HT on beta-cell proliferation and insulin secretion through both 5-HT2B and 5-HT3 receptors [2,51-53]. Moreover, it was shown that $5-\mathrm{HT}$ secreted from beta cells acts on neighboring alpha cells in a paracrine manner through the 5-HT1F receptor and subsides glucagon secretion, which consequently enhances insulin release [54]. Besides the receptor-dependent effects of $5-\mathrm{HT}$ on beta cells, Paulmann et al. in their study suggested that intracellular 5-HT modulates the secretion of insulin through the serotonylation of particular small GTPases (Rab family). Notably, Serotonylation, as a covalent linkage of 5-HT to target proteins, which is catalyzed by the transglutaminase enzymes, could activate GTPases and trigger exocytosis of insulin vesicles [46].

In contrast to the above-mentioned reports, some other studies reported that 5-HT or its agonists can decrease insulin secretion, and it also has the ability to induce hyperglycemia [42,55]. Some of these variations in the results of previous studies may be due to different study protocols, samples, cell lines, and animal models used in them. Another reason for these discrepancies may be due to complicated 5-HT and its receptors interactions.

At least 15 subtypes of 5-HT receptor which grouped in 7 different families play roles in 5-HT action and stimulation of different 5-HT receptors and they could provide augmentation to distinct cellular responses [56]. Recently, mRNA of all 5-HT receptor families (5-HTR1-7) were identified in human islets [56]. Furthermore, it was indicated that the response to metabolic status may be altered by the expression of particular receptors, and this event more complicates the situation. For example, Kim et al. indicated that the expression of the $5-\mathrm{HT} 2 \mathrm{~B}$ receptor increases during mid-gestation, in order to provoke $\beta$-cell proliferation and elevate the $\beta$-cell mass, while 5-HT1D receptor expression boosts at the end of gestation to lessen the $\beta$-cell mass [52]. In another study, Bennet et al. demonstrated that both 5-HT1D and 5-HT2A receptors, which stimulate and inhibit insulin secretion, respectively, showed over-expression in islets tissue from T2D donors compared to normal group [57]. 
Finally, a recent theory suggested that high extracellular $5-\mathrm{HT}$ concentrations $[5-\mathrm{HT}]_{\mathrm{e}}$ could diminish extra insulin release through $5-\mathrm{HT}_{1 \mathrm{~A}}$ receptors. In contrast, when intracellular $5-\mathrm{HT}[5-\mathrm{HT}]_{\mathrm{i}}$ attains much higher levels compared to $[5-\mathrm{HT}]_{\mathrm{e}}$ in beta cells, insulin secretion can be made by serotonylation. These findings suggested that both the inhibition and stimulation of 5-HT-dependent cycling could contribute to the recognized oscillating landscape of insulin exocytosis from glucose-stimulated $\beta$-cells [46]. Fig. 4 represents the possible mechanisms that could be involved in the regulation of insulin by different 5-HT receptors.

Taken together, 5-HT plays significant roles in insulin secretion and glucose hemostasis. Moreover, dysregulations of 5-HT pathway may be involved in diabetes pathogenesis, so it should be considered as a potential target for novel antidiabetic drugs. In this regard, further studies are needed to clear the exact roles of 5-HT and its receptors in both insulin secretion and glucose hemostasis.

\section{Limitations, Future Perspective, And Conclusions}

Based on the evaluated studies, it is difficult to express the exact alteration of 5-HT and Trp levels in plasma, serum or even tissue of human and animal samples due to the multi-dimensional nature of T2D. However, the results show that changes in 5-HT and Trp levels in different samples trigger variations in cell levels leading to the reduced insulin sensitivity as well as the increased insulin resistance, fat accumulation, and the development of metabolic syndromes. It seems that 5-HT and Trp may be considered as the markers of pathological changes of diabetes in cell's level.

The effects of 5-HT and Trp, which are present in the body, on the regulation of behavior and physiology have been in the center of scientific attention for decades. Although there have been reports on the involvement of both 5-HT and Trp metabolites in relation to diabetes, no systematic research on the roles of 5-HT and Trp in the pathogenesis of DM has been conducted yet.

Identification of T2D biomarkers due to the heterogeneity of the nature of T2D, is a big challenge. Another point to be considered is clinical phenotypes of disease comprising of age and BMI, as well as considering biochemical features, including insulin resistance and the effect of various environmental exposures. Accordingly, all of them lead to disease's variability. In these circumstances, the findings of recent studies could not help us in clarifying how a group of biomarkers may interact in other biological pathways or interact with biomarkers, in order to intensify diabetes progress. Therefore, to overcome such challenges, some studies have suggested that the use of data clustering methods can affect DM to control the role of underlying variables in relevant studies. So, a well-organized of these variables could provide a suitable way for biomarker's determination in DM. Another suggestion for biomarker research studies is the use of the network analysis to evaluate the cumulative effect of the different biomarkers on the enhancement of early diagnosis of DM complications.

Up to now, no systematic reviews/clinical trials have been conducted by considering Trp and 5-HT levels as trigger biomarkers for DM complications. Recently obtained results from Trp and 5-HT determination supported the clinical significance of both Trp and 5-HT levels in human metabolism; however, most of these studies had small sample sizes. Moreover, they have not considered all required items for the identification of the direct relationship between Trp and 5-HT levels in DM patients. Therefore, to improve the understanding on the roles 
of 5-HT and Trp in metabolism and to offer real diagnostic and therapeutic applications of 5-HT, more systematic studies are needed to control the serotonergic system, and genetic studies are required to explore the associations between 5-HT and L-Trp in DM with or without complications. In addition, it is necessary to figure out the precise evaluation of the effect of $5-\mathrm{HT}$ on insulin resistance. We hope that the observation from this study helps scientists and researchers to provide a suitable route for early diagnosis of DM with or without complications in each step.

\section{Declarations}

\section{Ethics approval and consent to participate}

Not Applicable.

\section{Consent for publication}

All the authors have approved this review article and agreed with submission.

\section{Availability of data and materials}

Not Applicable.

\section{Acknowledgments}

This work was nonfinancially supported by Endocrinology and Metabolism Research Institute, Tehran University of Medical Sciences.

\section{Competing interests}

The authors declare that they have no competing interests.

\section{Funding}

Private funds were applied to carry out this study.

\section{Authorship contribution statement}

KK: Conceptualization, Investigation, Methodology, Design, Writing-review \&editing. MCG: Investigation, Methodology, Design, Writing-review \&editing. SMSJ: Investigation, Methodology, Writing-review \&editing.

\section{References}

1. Berger M, Gray JA, Roth BL. The Expanded Biology of Serotonin. Annu Rev Med Annual Reviews. 2009;60:355-66.

2. Kim K, Oh C-M, Ohara-Imaizumi M, Park S, Namkung J, Yadav VK, et al. Functional Role of Serotonin in Insulin Secretion in a Diet-Induced Insulin-Resistant State. Endocrinology. 2015;156:444-52.

3. Pietraszek MH, Takada Y, Takada A, Fujita M, Watanabe I, Taminato A, et al. Blood serotonergic mechanisms in type 2 (non-insulin-dependent) diabetes mellitus. Thromb Res Elsevier. 1992;66:765-74. 
4. Hara K, Hirowatari Y, Shimura Y, Takahashi H. Serotonin levels in platelet-poor plasma and whole blood in people with type 2 diabetes with chronic kidney disease. Diabetes Res Clin Pract. 2011;94:167-71.

5. BARRADAS MA, GILL DS, FONSECA VA, MIKHAILIDIS DP, DANDONA P. Intraplatelet serotonin in patients with diabetes mellitus and peripheral vascular disease. Eur J Clin Invest. John Wiley \& Sons, Ltd; 1988;18:399-404.

6. Khoshnevisan K, Maleki H, Honarvarfard E, Baharifar H, Gholami M, Faridbod F, et al. Nanomaterial based electrochemical sensing of the biomarker serotonin: a comprehensive review. Microchim Acta. 2019;186:49.

7. Danaceau JP, Anderson GM, McMahon WM, Crouch DJ. A liquid chromatographic-tandem mass spectrometric method for the analysis of serotonin and related indoles in human whole blood. J Anal Toxicol. 2003.

8. Labib M, Sargent EH, Kelley SO. Electrochemical Methods for the Analysis of Clinically Relevant Biomolecules. Chem Rev American Chemical Society. 2016;116:9001-90.

9. Khoshnevisan K, Honarvarfard E, Torabi F, Maleki H, Baharifar H, Faridbod F, et al. Electrochemical detection of serotonin: A new approach. Clin Chim Acta. 2020;501:112-9.

10. Huang H, Chen Z, Yan X. Simultaneous determination of serotonin and creatinine in urine by combining two ultrasound-assisted emulsification microextractions with on-column stacking in capillary electrophoresis. J Sep Sci. John Wiley \& Sons, Ltd; 2012;35:436-44.

11. Rognum IJ, Tran H, Haas EA, Hyland K, Paterson DS, Haynes RL, et al. Serotonin Metabolites in the Cerebrospinal Fluid in Sudden Infant Death Syndrome. J Neuropathol Exp Neurol England. 2014;73:11522.

12. Runions KC, Morandini HAE, Rao P, Wong JWY, Kolla NJ, Pace G, et al. Serotonin and aggressive behaviour in children and adolescents: a systematic review. Acta Psychiatr Scand. John Wiley \& Sons, Ltd; 2019;139:117-44.

13. O'Mahony SM, Clarke G, Borre YE, Dinan TG, Cryan JF. Serotonin, tryptophan metabolism and the braingut-microbiome axis. Behav Brain Res. Alimentary Pharmabiotic Centre, University College Cork, Cork, Ireland: Elsevier; 2015;277:32-48.

14. Sorgdrager FJH, Naudé PJW, Kema IP, Nollen EA, Deyn PP, De. Tryptophan Metabolism in Inflammaging: From Biomarker to Therapeutic Target. Front Immunol. 2019;10:2565.

15. Khoshnevisan K, Torabi F, Baharifar H, Sajjadi-Jazi SM, Afjeh MS, Faridbod F, et al. Determination of the biomarker L-tryptophan level in diabetic and normal human serum based on an electrochemical sensing method using reduced graphene oxide/gold nanoparticles/18-crown-6. Anal Bioanal Chem. 2020;412:3615-27.

16. Khoshnevisan K, Baharifar H, Torabi F, Sadeghi Afjeh M, Maleki H, Honarvarfard E, et al. Serotonin level as a potent diabetes biomarker based on electrochemical sensing: a new approach in a zebra fish model. Anal Bioanal Chem. 2021;413:1615-27.

17. Hara K, Hirowatari Y, Shimura Y, Takahashi H. Serotonin levels in platelet-poor plasma and whole blood in people with type 2 diabetes with chronic kidney disease. Diabetes Res Clin Pract Elsevier. 2011;94:167-71.

18. Leitner M, Fragner L, Danner S, Holeschofsky N, Leitner K, Tischler S, et al. Combined Metabolomic Analysis of Plasma and Urine Reveals AHBA, Tryptophan and Serotonin Metabolism as Potential Risk 
Factors in Gestational Diabetes Mellitus (GDM). Front Mol Biosci Frontiers Media SA. 2017;4:84.

19. Saito J, Suzuki E, Tajima Y, Takami K, Horikawa Y, Takeda J. Increased plasma serotonin metabolite 5hydroxyindole acetic acid concentrations are associated with impaired systolic and late diastolic forward flows during cardiac cycle and elevated resistive index at popliteal artery and renal insufficiency in type 2. Endocr J. 2016;63:69-76.

20. Zahn D, Petrak F, Franke L, Hägele A-K, Juckel G, Lederbogen F, et al. Cortisol, Platelet Serotonin Content, and Platelet Activity in Patients With Major Depression and Type 2 Diabetes. Psychosom Med. 2015;77:145-55.

21. Fukui M, Shiraishi E, Tanaka M, Senmaru T, Sakabe K, Harusato I, et al. Plasma serotonin is a predictor for deterioration of urinary albumin excretion in men with type 2 diabetes mellitus. Metabolism Elsevier. 2009;58:1076-9.

22. Yanai H, Hirowatari Y. A significant association of plasma serotonin to cardiovascular risk factors and changes in pulse wave velocity in patients with type 2 diabetes. Int J Cardiol Elsevier. 2012;157:312-3.

23. Takada A, Shimizu F, Masuda J, Matsuoka K. Plasma Levels of Tryptophan Metabolites in Patients of Type 2 Diabetes Mellitus. Bioact Food as Diet Interv Diabetes. Elsevier; 2019. pp. 265-76.

24. Unluturk U, Erbas T. Diabetes and tryptophan metabolism. Cham (Switzerland): Humana Press; 2015.

25. Matsuoka K, Kato K, Takao T, Ogawa M, Ishii Y, Shimizu F, et al. Concentrations of various tryptophan metabolites are higher in patients with diabetes mellitus than in healthy aged male adults. Diabetol Int. 2017;8:69-75.

26. Sakurai S, Inai Y, Minakata S, Manabe S, Ito Y, Ihara Y. A novel assay for detection and quantification of Cmannosyl tryptophan in normal or diabetic mice. Sci Rep. Nature Publishing Group; 2019;9.

27. Chou CA, Lin CN, Chiu DTY, Chen IW, Chen ST. Tryptophan as a surrogate prognostic marker for diabetic nephropathy. J Diabetes Investig Blackwell Publishing. 2018;9:366-74.

28. Rebnord EW, Strand E, Midttun Ø, Svingen GFT, Christensen MHE, Ueland PM, et al. The kynurenine:tryptophan ratio as a predictor of incident type 2 diabetes mellitus in individuals with coronary artery disease. Diabetologia Springer Verlag. 2017;60:1712-21.

29. Chen T, Zheng X, Ma X, Bao Y, Ni Y, Hu C, et al. Tryptophan Predicts the Risk for Future Type 2 Diabetes. PLoS One. Public Library of Science; 2016;11.

30. Mancuso P, Bouchard B. The impact of aging on adipose function and adipokine synthesis. Front. Endocrinol. (Lausanne). Frontiers Media S.A.; 2019.

31. Ramos-Chávez LA, Roldán-Roldán G, García-Juárez B, González-Esquivel D, Pérez de la Cruz G, Pineda B, et al. Low serum tryptophan levels as an indicator of global cognitive performance in nondemented women over 50 years of age. Oxid Med Cell Longev. Hindawi Limited; 2018;2018.

32. Yu E, Papandreou C, Ruiz-Canela M, Guasch-Ferre M, Clish CB, Dennis C, et al. Association of tryptophan metabolites with incident type 2 diabetes in the PREDIMED trial: A case-cohort study. 64: Clin Chem. American Association for Clinical Chemistry Inc.; 2018. pp. 1211-20.

33. Floegel A, Stefan N, Yu Z, Mühlenbruch K, Drogan D, Joost HG, et al. Identification of serum metabolites associated with risk of type 2 diabetes using a targeted metabolomic approach. Diabetes Diabetes. 2013;62:639-48. 
34. F S. Plasma Levels of Tryptophan Metabolites in Healthy Young and Old Men and Women, and Patients of Type 2 Diabetes Mellitus (T2DM). Obes Open Access. Sci Forschen, Inc.; 2018;4.

35. Takada A, Shimizu F, Takao T, Masuda J. Measurement of Tryptophan Metabolites in Healthy Old Men and Patients of Type 2 Diabetes Mellitus (T2DM). Food Nutr Sci. Scientific Research Publishing, Inc;; 2018;09:pp. 1206-20.

36. Calvani R, Rodriguez-Mañas L, Picca A, Marini F, Biancolillo A, Laosa O, et al. Identification of a circulating amino acid signature in frail older persons with type 2 diabetes mellitus: Results from the metabofrail study. 12: Nutrients. MDPI AG; 2020.

37. Sipahi H, Girgin G, Inanici F, Ariogul S, Sahin G, Baydar T. Tryptophan degradation and neopterin levels by aging. Pteridines De Gruyter. 2013;24:33-9.

38. Donath MY, Shoelson SE. Type 2 diabetes as an inflammatory disease. Nat. Rev. Immunol. Nat Rev Immunol; 2011. p. 98-107.

39. Oxenkrug GF. Metabolic syndrome, age-associated neuroendocrine disorders, and dysregulation of tryptophan - Kynurenine metabolism. Ann N Y Acad Sci. Blackwell Publishing Inc.; 2010. pp. 1-14.

40. Fuertig R, Azzinnari D, Bergamini G, Cathomas F, Sigrist H, Seifritz E, et al. Mouse chronic social stress increases blood and brain kynurenine pathway activity and fear behaviour: Both effects are reversed by inhibition of indoleamine 2,3-dioxygenase. 54: Brain Behav Immun. Academic Press Inc.; 2016. pp. 59-72.

41. Robinson R. Serotonin's role in the pancreas revealed at last. PLoS Biol. 2009.

42. Zhang Q, Zhu Y, Zhou W, Gao L, Yuan L, Han X. Serotonin Receptor 2C and Insulin Secretion. PLoS One Public Library of Science. 2013;8:e54250.

43. Mohamed RA, Galal O, Mohammed AR, El-Abhar HS. Tropisetron modulates peripheral and central serotonin/insulin levels via insulin and nuclear factor kappa B/receptor for advanced glycation end products signalling to regulate type- 2 diabetes in rats. RSC Adv The Royal Society of Chemistry. 2018;8:11908-20.

44. GYLFE E. ASSOCIATION BETWEEN 5-HYDROXYTRYPTAMINE RELEASE AND INSULIN SECRETION. J Endocrinol. Bristol, UK: Bioscientifica Ltd; 78:239-48.

45. Sugimoto Y, Kimura I, Yamada J, WATANABE Y, TAKEUCHI N. HORISAKA K. Effects of serotonin on blood glucose and insulin levels of glucose and streptozotocin-treated mice. Jpn J Pharmacol The Japanese Pharmacological Society. 1990;54:93-6.

46. Paulmann N, Grohmann M, Voigt J-P, Bert B, Vowinckel J, Bader M, et al. Intracellular Serotonin Modulates Insulin Secretion from Pancreatic $\beta$-Cells by Protein Serotonylation. PLOS Biol Public Library of Science. 2009;7:e1000229.

47. Malyszko J, Urano T, Knofler R, Taminato A, Yoshimi T, Takada Y, et al. Daily variations of platelet aggregation in relation to blood and plasma serotonin in diabetes. Thromb Res. 1994;75:569-76.

48. Marti'n FJ, Mi'guez JM, Aldegunde M, Atienza G. Effect of streptozotocin-induced diabetes mellitus on serotonin measures of peripheral tissues in rats. Life Sci. 1994;56:51-9.

49. Moon JH, Kim YG, Kim K, Osonoi S, Wang S, Saunders DC, et al. Serotonin Regulates Adult $\beta$-Cell Mass by Stimulating Perinatal $\beta$-Cell Proliferation. Diabetes. 2020;69:205 LP - 214. 
50. Ohara-Imaizumi M, Kim H, Yoshida M, Fujiwara T, Aoyagi K, Toyofuku Y, et al. Serotonin regulates glucosestimulated insulin secretion from pancreatic $\beta$ cells during pregnancy. Proc Natl Acad Sci. 2013;110:19420 LP - 19425.

51. Bennet H, Mollet IG, Balhuizen A, Medina A, Nagorny C, Bagge A, et al. Serotonin (5-HT) receptor 2b activation augments glucose-stimulated insulin secretion in human and mouse islets of Langerhans. Diabetologia Springer. 2016;59:744-54.

52. Kim H, Toyofuku Y, Lynn FC, Chak E, Uchida T, Mizukami H, et al. Serotonin regulates pancreatic beta cell mass during pregnancy. Nat Med. 2010;16:804-8.

53. Ma N, Ma X. Dietary Amino Acids and the Gut-Microbiome-Immune Axis: Physiological Metabolism and Therapeutic Prospects. Compr Rev Food Sci Food Saf. State Key Laboratory of Animal Nutrition, College of Animal Science and Technology, China Agricultural Univ., Beijing, 100193, China: Blackwell Publishing Inc.; 2019;18:pp. 221-42.

54. Almaça J, Molina J, Menegaz D, Pronin AN, Tamayo A, Slepak V, et al. Human Beta Cells Produce and Release Serotonin to Inhibit Glucagon Secretion from Alpha Cells. Cell Rep. 2016;17:3281-91.

55. Heimes K, Feistel B, Verspohl EJ. Impact of the 5-HT3 receptor channel system for insulin secretion and interaction of ginger extracts. Eur J Pharmacol. 2009;624:58-65.

56. Cataldo Bascuñan LR, Lyons C, Bennet H, Artner I, Fex M. Serotonergic regulation of insulin secretion. Acta Physiol. John Wiley \& Sons, Ltd; 2019;225:e13101.

57. Bennet H, Balhuizen A, Medina A, Dekker Nitert M, Ottosson Laakso E, Essén S, et al. Altered serotonin (5HT) $1 \mathrm{D}$ and $2 \mathrm{~A}$ receptor expression may contribute to defective insulin and glucagon secretion in human type 2 diabetes. Peptides. 2015;71:113-20.

\section{Tables}

Table 1. Findings of 5-HT/5HIAA levels in different studies including animal and human studies with DM 


\begin{tabular}{|c|c|c|c|c|c|}
\hline $\begin{array}{l}\text { tabolite } \\
\mathrm{n} \text { the } \\
\mathrm{c} \text { and } \\
\text { group } \\
-1 \text { ) }\end{array}$ & $\begin{array}{l}\text { Determination } \\
\text { Method }\end{array}$ & $\begin{array}{l}\text { Types of diabetes or } \\
\text { complications }\end{array}$ & Sample & Main finding & Refs \\
\hline $\begin{array}{l}1.93 \pm \\
\text { healthy: } \\
0.30\end{array}$ & $\begin{array}{l}\text { Electrochemical } \\
\text { sensing and } \\
\text { HPLC }\end{array}$ & T2D & $\begin{array}{l}\text { GI of } \\
\text { ZF }\end{array}$ & $\begin{array}{l}\text { Significant reduction in the 5-HT } \\
\text { level in diabetic ZF }\end{array}$ & {$[16]$} \\
\hline$t$ & $\begin{array}{l}\text { A stable isotope } \\
\text { dilution direct- } \\
\text { infusion method } \\
\text { (SIDE-MS } \\
\text { assay) }\end{array}$ & GDM & $\begin{array}{l}\text { Plasma } \\
\text { and } \\
\text { urine }\end{array}$ & $\begin{array}{c}\text { Displaying higher 5-HT levels } \\
\text { about disrupted metabolisms, like } \\
\text { GDM }\end{array}$ & [18] \\
\hline $\begin{array}{l}\text { as a } \\
\text { of } 5-\mathrm{HT} \\
0 \text { and } \\
1.4\end{array}$ & HPLC & $\begin{array}{l}\mathrm{T} 2 \mathrm{D} / \text { normoalbuminuric } \\
\text { and microalbuminuric } \\
\text { patients }\end{array}$ & WB & $\begin{array}{l}\text { Increasing plasma 5-HIAA } \\
\text { concentrations associated with } \\
\text { impaired systolic and late } \\
\text { diastolic, and increasing the } \\
\text { resistance of peripheral vascular } \\
\text { in diabetic patients }\end{array}$ & [19] \\
\hline $\begin{array}{l}\mathrm{d} 379.5 \\
\left.0^{9}\right)\end{array}$ & HPLC & $\begin{array}{c}\mathrm{T} 2 \mathrm{D} \\
\text { and depression }\end{array}$ & PPP & $\begin{array}{c}\text { Finding association } \\
\text { between cortisol or 5-HT and } \\
\text { platelet markers }\end{array}$ & [20] \\
\hline $\begin{array}{l}\text { and } 8.5 \\
\text { betic } \\
\text { ind } 4.8 \\
\text { lealthy } \\
\text { 1 PPP. } \\
\text { and } 582 \\
\text { betic } \\
\text { nd } 713 \\
\text { lealthy } \\
\text { n WB }\end{array}$ & HPLC & $\begin{array}{l}\text { T2D complicated with } \\
\text { chronic kidney (divided } \\
\text { into } 3 \text { groups and } 1 \\
\text { healthy group }\end{array}$ & $\begin{array}{l}\mathrm{PPP}, \\
\mathrm{WB}\end{array}$ & $\begin{array}{l}\text { Reduction of the } 5 \text {-HT level in } \\
\text { the plasma and raising } 5 \text {-HT level } \\
\text { in WB, perhaps by suppressing } \\
\text { platelet aggregation by } \\
\text { administration of iloprost }\end{array}$ & [17] \\
\hline $\begin{array}{l}.9 \pm 5.4 \\
\text { na } 3.5 \pm \\
3 \\
\text { plasma } \\
0.7 \\
\text { ma } 11.6 \\
.3\end{array}$ & HPLC & T2D- nephropathy & Plasma & $\begin{array}{c}\text { Demonstrating relation between } \\
\text { plasma 5-HIAA concentration and } \\
\text { urinary albumin excretion }\end{array}$ & [21] \\
\hline $\begin{array}{l}\text { ative } \\
\text { ration }\end{array}$ & HPLC & ACD- T2D & Plasma & $\begin{array}{l}\text { Presenting a major association } \\
\text { between plasma 5-HT and } \\
\text { atherosclerosis in diabetic } \\
\text { patients }\end{array}$ & [22] \\
\hline
\end{tabular}

HPLC, High Performance Liquid Chromatography; T2D, Type 2 diabetes; WB, Whole Blood; PPP, platelet-rich plasma; 5-HIAA, 5-Hydroxyindoleacetic acid; ACD, atherosclerotic cardiovascular disease; GI, Gastrointestinal; ZF, Zebrafish; GDM, Gestational diabetes mellitus

Table 2. Findings of Trp levels in different studies including animal and human studies with DM 
HS, Human Serum; HP, Human Plasma; HU, Human Urine; C-Man-Trp, UHS, Ultrahigh speed; C-mannosyltryptophan; eGFR, estimated glomerular filtration rate; KTR, kynurenine/tryptophan ratio; 5-HTP, 5hydroxytryptophan; PLS-DA, Partial least squares-discriminant analysis; LC, liquid chromatography; MS/MS, tandem mass spectrometry; UPLC-TQ/MS, ultra-performance liquid chromatography triple quadruple mass spectrometry; PLSDA, Partial Least Squares-Discrimination Analysis

\section{Figures}

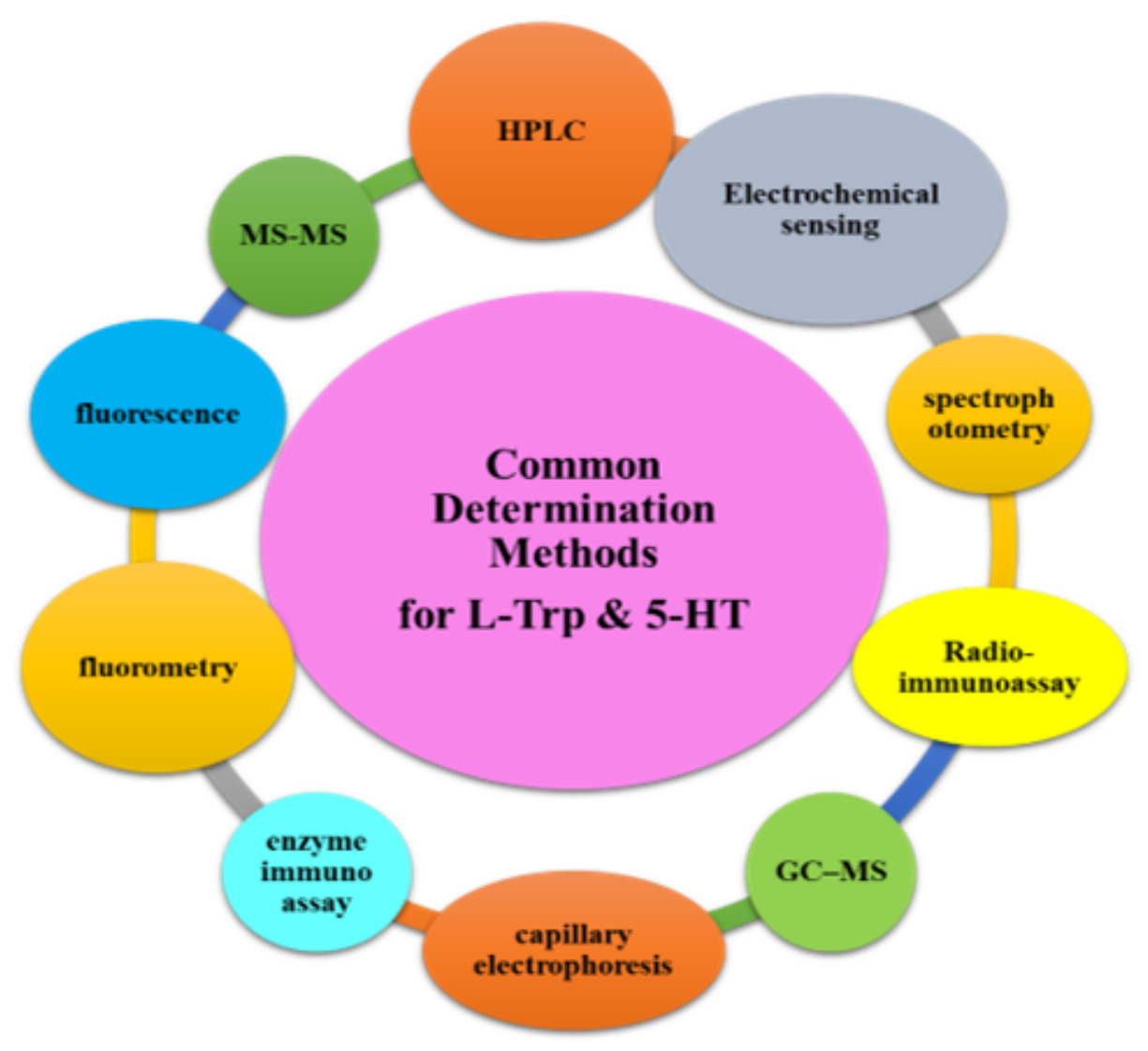

Figure 1

An outline of 5-HT and L-Trp determination methods 


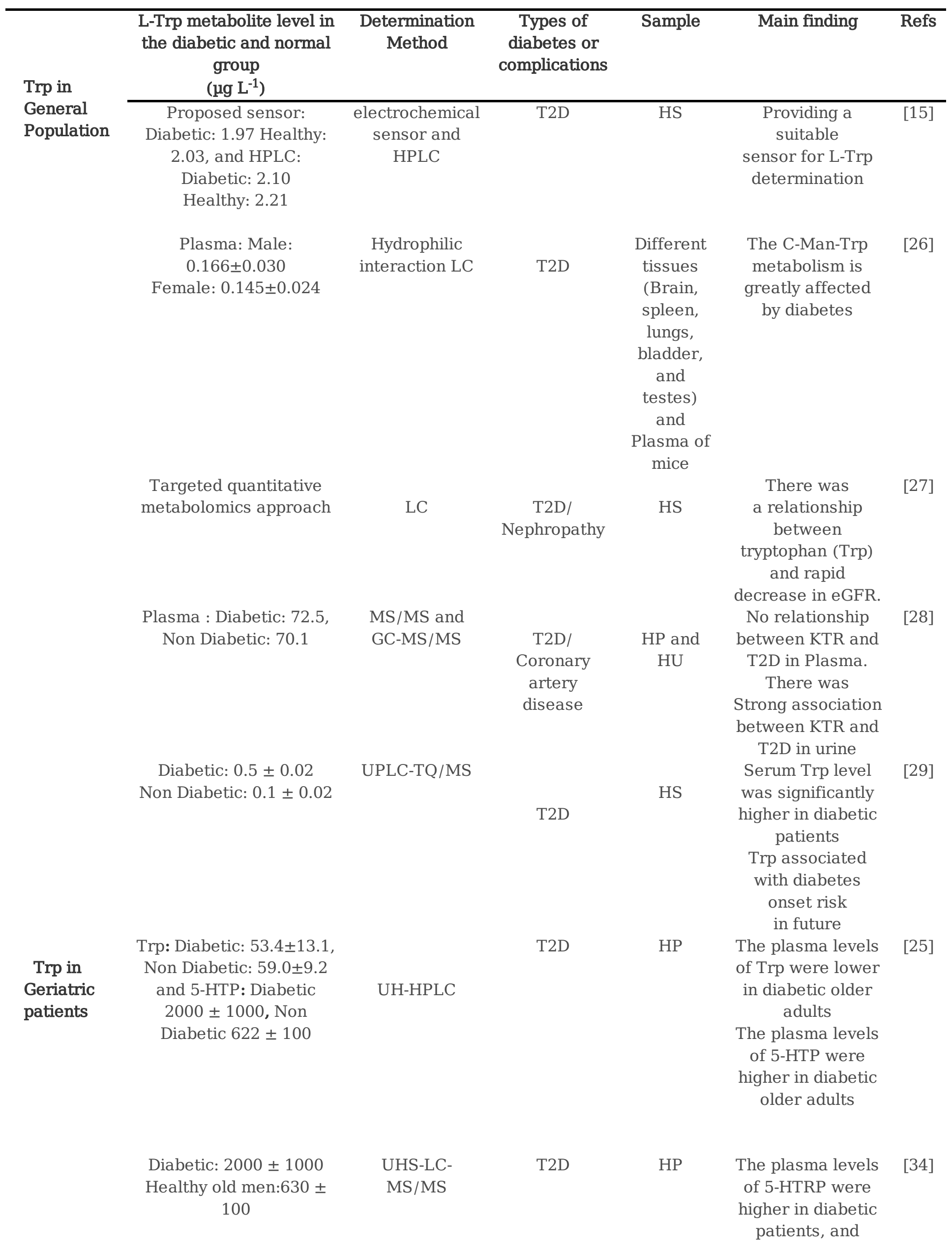


Diabetic: $0.048 \pm 0.038$

Non Diabetic: $0.014 \pm$ 0.029

Diabetic: $66.2 \pm 23.4$

Non Diabetic: $62.0 \pm$ 13.1

Diabetic: $51.7 \pm 2.6$

Non F=Diabetic:

$58.3 \pm 1.6$
LC-MS/MS

PLS-DA

Frail older adults with

T2D

T2D
Fasting HP the level of 5-

HTRP were higher

in plasma

HS

The level of Trp was higher in serum of diabetic patients

HS

HPLC

The levels of Trp and Kyn/Trp were higher than healthy older adults

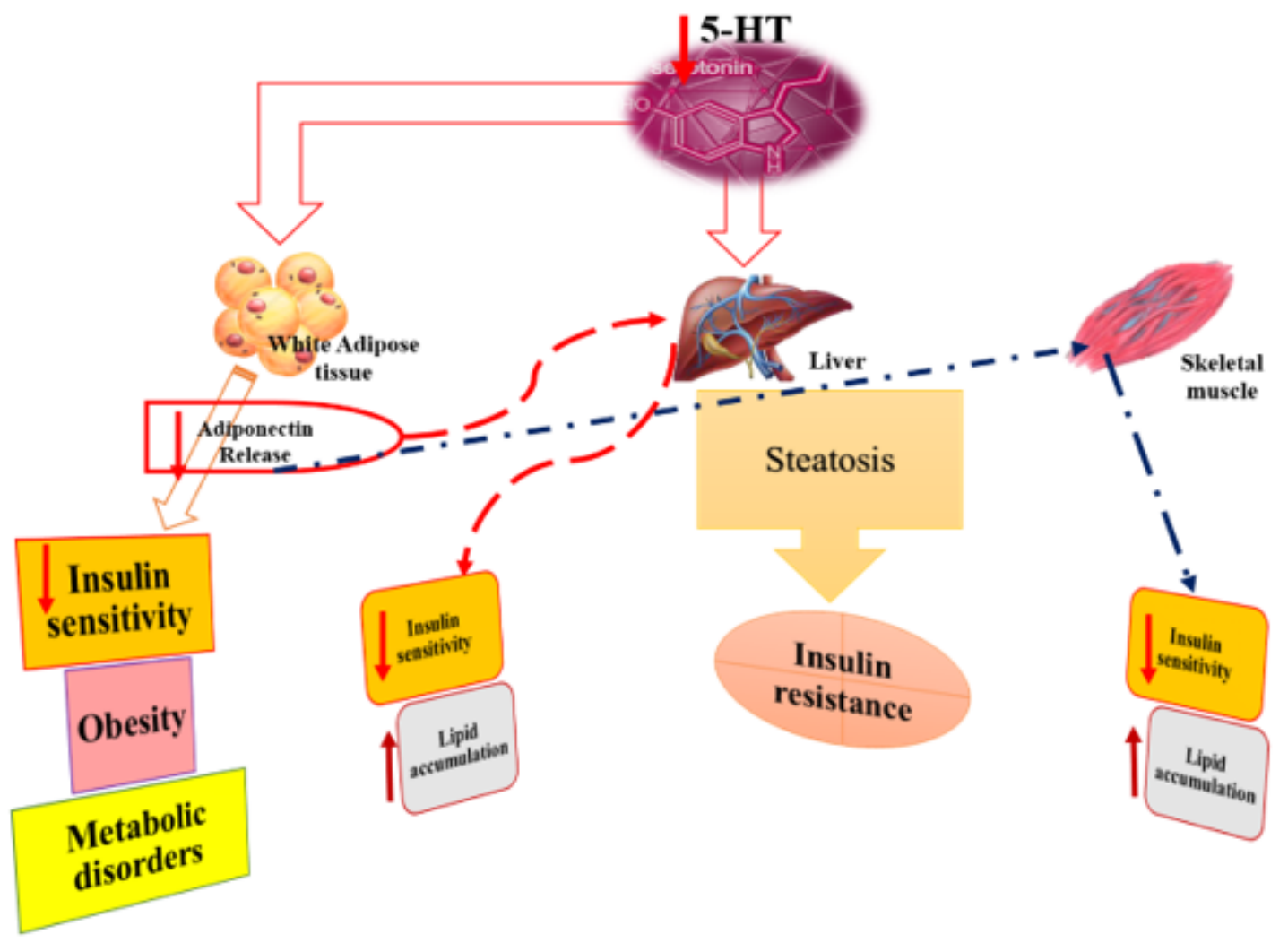

Figure 2

The relationship between 5-HT alteration and probability of the T2D pathogenesis in different tissues 


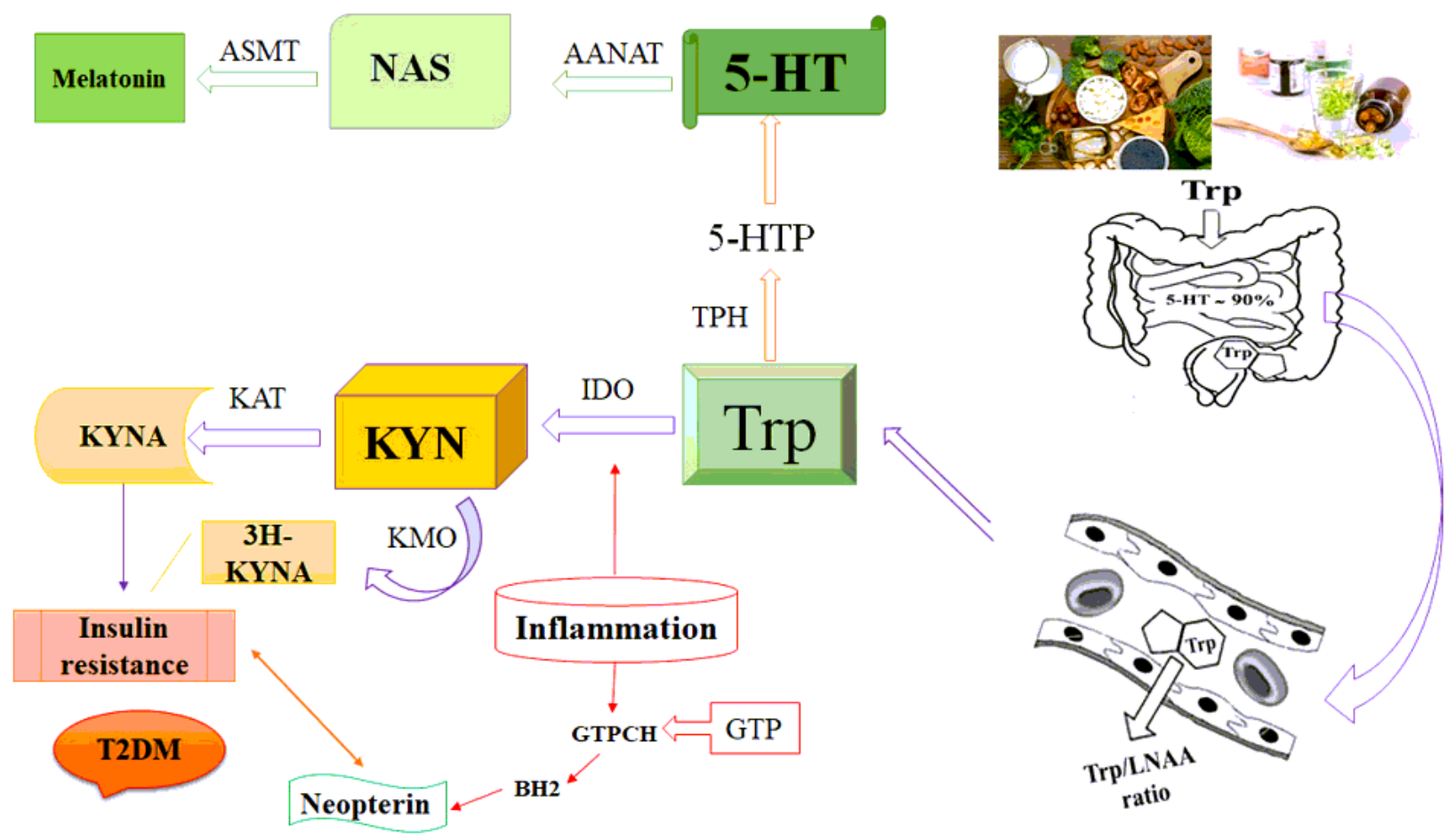

Figure 3

The relationship of Trp-KYN metabolic pathways with T2D. Abbreviations: KYN, Kynurenine; IDO, indoleamine 2,3-dioxygenase; KAT, KYN-aminotransferase; KMO, KYN-3-monooxygenase; 3H-KYNA, 3-hydroxyKYN acid (xanthurenic acid); IR, insulin resistance; TpH, Tryptophan Hydroxylase; AAAD, Aromatic Amino Acid Decarboxylase; AANAT, Aralkylamine N-Acetyltransferase; ASMT, Acetylserotonin O-Methyltransferase; GTP, guanosine triphosphate; GTPCH, GTP cyclohydrolase I; $\mathrm{BH} 2$, 7,8-dihydroneopterin. 


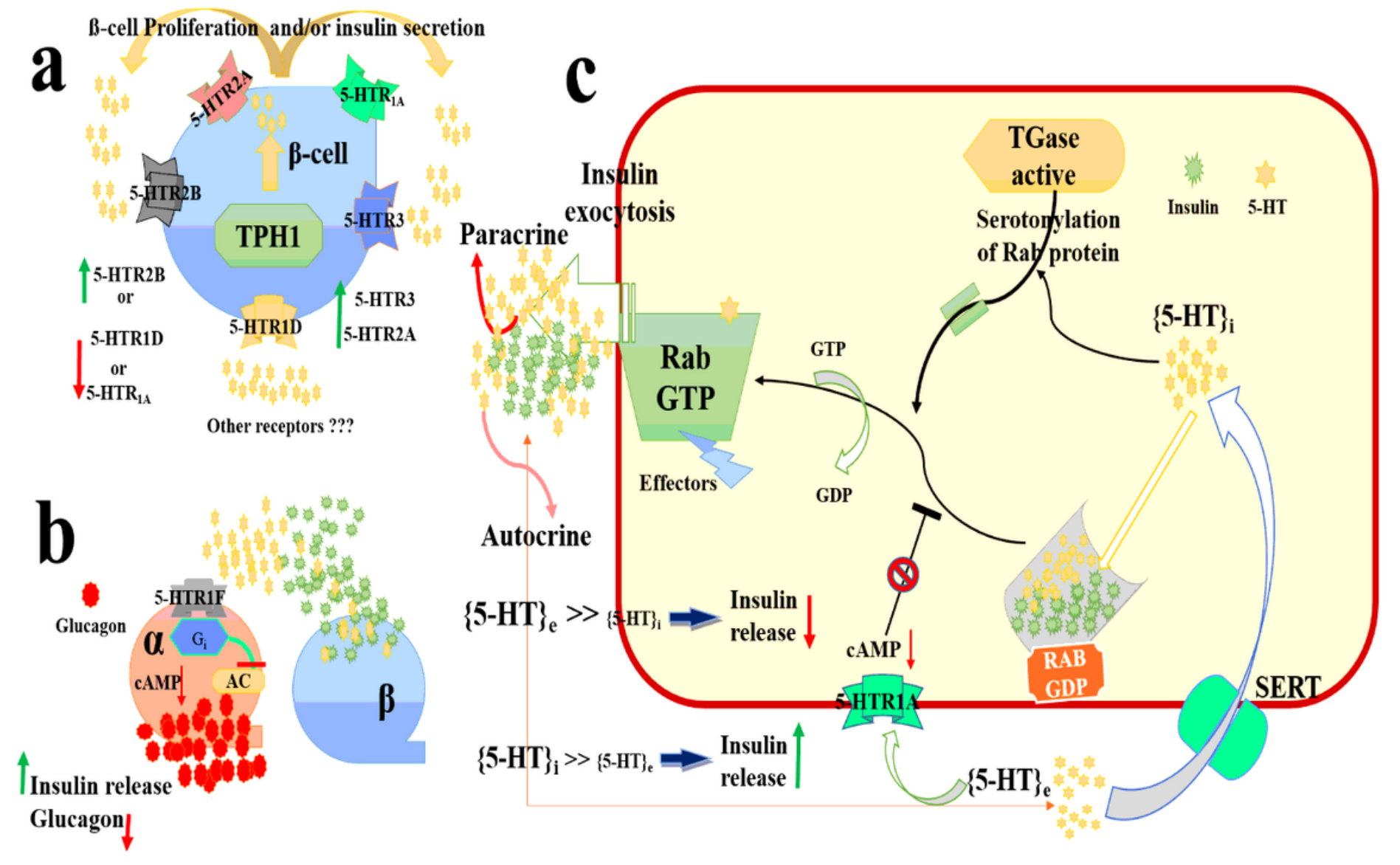

\section{Figure 4}

Schematic illustration of a) Effect of the main 5-HT receptors classes on $\beta$-cell proliferation, b) effect of 5HTR1F on glucagon in a-cell, and c) The relationship between the reduction and augmentation of insulin release depending on [5-HT]e and [5-HT]i. Abbreviations: 5-HTi, 5-Hydroxytryptophan intracellular; 5-HTe, 5Hydroxytryptophan extracellular; SERT, 5-HT Transporter; cAMP, Cyclic Adenosine Monophosphate; GDP, Guanosine diphosphate; GTP, Guanosine 5'-Triphosphate; T Gase, Transglutaminase; TPH1, Tryptophan Hydroxylase 1; 5HTR2B, 5-Hydroxytryptamine receptor 2B; 5HTR3, 5-Hydroxytryptamine Receptor 3; 5-HTR1D, 5-Hydroxytryptamine Receptor 1D; AC, adenylate cyclase; Gi, inhibitory G protein.

\section{Supplementary Files}

This is a list of supplementary files associated with this preprint. Click to download.

- TableofContents.jpg 